\title{
The Value of IncRNA HULC as a Prognostic Factor for Survival of Cancer Outcome: A Meta-Analysis
}

\author{
Xian Chen Limin Lun Huabin Hou Runhua Tian Haiping Zhang Yunyuan Zhang \\ Department of Clinical Laboratory, the Affiliated Hospital of Qingdao University, Qingdao, China
}

Key Words

LnCRNA • HULC • Overall survival

\begin{abstract}
Aims: Growing evidence from recent studies has shown that IncRNA HULC plays a role in the development of multiple carcinomas. This meta-analysis aimed to analyze available data to identify the prognostic value of HULC in multiple tumors. Methods: A systematic search was performed by using PubMed (medline), Embase, ISI Web of Knowledge, Springer, the Cochrane Library, Scopus, BioMed Central, ScienceDirect, Wanfang, Weipu, and China National Knowledge Internet (CNKI) computerized databases from inception to Nov 30, 2016. The quality of the publications was assessed according to the critical review checklist of the Dutch Cochrane Centre proposed by MOOSE and PRISMA. Pooled hazard ratios (HR) with $95 \%$ confidence interval $(95 \%$ CI) were calculated to summarize the effect. Results: A total of ten studies with 1077 cancer patients were pooled in the present meta-analysis to evaluate the prognostic value of HULC in multiple tumors. High expression levels of HULC were demonstrated to be associated with poor overall survival (OS) (HR=2.44, 95\%CI: 1.963.03, $P=0.000$ ). Subgroup analysis showed that cancer type (digestive or non-digestive disease), residence region (China), sample size (more or less than 100) and follow-up months (more or less than 60 ) did not alter the predictive value of HULC on OS in various cancers. Additionally, increased HULC expression was found to be moderately associated with tumor stage and progression (III/IV vs. I/II: HR=1.59, 95\% CI: 1.31-1.92, $P<0.00001$ ). Furthermore, elevated HULC expression significantly predicted distant metastasis (HR=3.90, 95\% CI: 1.89 $8.02, P=0.0002)$ and lymph node metastasis ( $\mathrm{HR}=2.04,95 \% \mathrm{CI}: 1.03-4.05, P=0.04)$ respectively. No significant heterogeneity was observed among studies except lymph node metastasis. Conclusion: The results indicate that HULC expression level is an independent prognostic biomarker for unfavorable OS and metastasis in general tumors.
\end{abstract}

\section{Introduction}

(C) 2017 The Author(s)

Published by S. Karger AG, Basel

Cancer is becoming the leading cause of mortality and morbidity for human health over the past decade [1]. According to 2014 Cancer Statistics, an estimated 1,665,540 new cancer 


\section{Cellular Physiology Cell Physiol Biochem 2017;41:1424-1434 \begin{tabular}{c|c|c|} 
DOI: 10.1159/000468005 & O 2017 The Author(s). Published by S. Karger AG, Basel \\
www.karger.com/cpb
\end{tabular} \\ Chen et al.: A Meta-Analysis for HULC as a Prognostic Factor in Various Cancers}

cases and 585,720 cancer deaths are projected to occur in the United States [2]. To date, the mechanisms of oncogenesis and tumor progression have not been fully clarified and the widely used prognostic markers are still tumor node metastasis (TNM) stage and grade, histological differentiation grade, and tumor size etc. Thus, many scientists are devoted to identify new potential biomarker for forecasting prognosis and predicting the therapeutic efficacy for cancer patients to improve their survival status $[3,4]$.

Non-coding RNAs refer to different types of RNA which can not produce biologically meaningful RNA transcripts, usually including small interfering RNA (short interfering RNA, siRNA), PIWI-interacting RNA (piRNA), microRNA (miRNA) and long noncoding RNAs (lncRNAs) etc. [5, 6]. Recent articles have indicated that at least $95 \%$ of the human genome undergoes transcription to a huge array of RNA species and most of them are longer than 200 nucleotides [7]. Mounting evidence links expression changes of lncRNAs with complex diseases such as cancer. The dysregulation suggests that lncRNAs emerge as vital modulators in carcinomas and thus further emphasize the potential role of lncRNAs in tumorigenesis and tumor progression [8-10].

Highly up-regulated in liver cancer (HULC), as one of the most up-regulated ncRNAs, was first identified from an HCC-specific gene expression profiling [11, 12]. Recently, many observations indicate that the striking promoted expression pattern was associated with worse survival and high risk of cancer metastasis in patients with various carcinomas $[13,14]$. However, most individual studies assessing the implications of HULC levels in cancer have been limited by small sample sizes and the controversial results. Therefore, a comprehensive meta-analysis of all eligible articles was performed to further evaluate the clinical feasibility of HULC as a novel biomarker candidates as well as useful insights into the tumor clinicopathological features.

\section{Material and Methods}

\section{Search strategy and Literature selection}

Up to November 30,2016, potential eligible literatures which evaluated the IncRNA HULC as a putative biomarker for the prognosis and metastasis of various tumors, were searched in several computerized databases, including PubMed, Embase, Cochrane Library, ScienceDirect, BioMed Central, Springer, ISI Web of Knowledge, together with three Chinese databases: China National Knowledge Internet (CNKI), Wanfang and Weipu databases. The searched terms in variably combinations were listed as follows: ("long noncoding RNA-, Inc RNA-, highly up-regulated in liver cancer, HULC,") and ("cancer" or "carcinoma" or "tumor" or "neoplasm") and ("prognosis" or "prognostic" or "survival" or "metastasis"). The reference lists of primary literatures were manually searched for additional relevant articles.

\section{Inclusion and exclusion criteria}

Inclusion criteria are as following: 1) Articles investigating the expression pattern of HULC in any malignant tumor; 2) Definite diagnosis or histopathology confirmed for patients with cancer; 3) Sufficient data for the computation of hazard ratio (HR) and corresponding 95\% confidence intervals (CI); 4) Studies with enough information to construct the $2 \times 2$ contingency Table.

Exclusion criteria are as following: 1) Studies investigating the molecular structure and functions of HULC or literatures not pertinent to the HULC; 2) Studies of non dichotomous HULC expression and absence of survival outcome; 3) Duplicate publications as well as multiple duplicate data in the different works, excluding earlier and smaller sample data; 4) Correspondences, animal experiments, letters, editorials, expert opinions, talks, reviews and case reports without original data.

\section{Data extraction and Quality Assessment}

Two investigators (XC and YYZ) extracted all the essential information from identified articles independently. According to the inclusion and exclusion criteria, the following information from each enrolled study was extracted: (1) first authors, publication year, study population, patients and controls size, tumor type, follow-up month; (2) HULC assessment method and specimen; (3) HR and their 95\% 


\section{Cellular Physiology Cell Physiol Biochem 2017;41:1424-1434

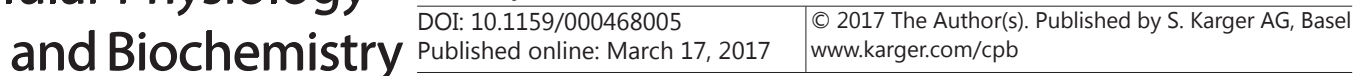 \\ Chen et al.: A Meta-Analysis for HULC as a Prognostic Factor in Various Cancers}

CI of HULC value for overall survival (OS), distant metastasis (DM) or lymph node metastasis (LNM). If any essential information were not available from the original article, best efforts were made to contact the corresponding author to obtain the missing data. If only Kaplan-Meier curves were provided in some studies, the survival rates were extracted from the graphical survival plots and the calculated HR and 95\% CI was determined as the published methods $[15,16]$. As shown in supplementary materials (Checklist Table 5 and Table 6), all the included publications were evaluated based on the critical checklist of the Dutch Cochrane Centre proposed by MOOSE and PRISMA.

\section{Statistical analysis}

The present analyses were performed using Stata SE12.0 (Stata Corporation) and RevMan5.1 software. The impact of HULC expression on clinical prognosis and metastasis was described as HR and corresponding 95\% CI. The combined effect size (ES) was considered as HR and should be statistically significant when the $95 \% \mathrm{CI}$ did not overlap with 1 . Heterogeneity across the enrolled studies was quantified with the $I^{2}$ statistics. The fix-effects model with the inverse variance method was conducted to analyze the relationship between HULC expression and clinical outcomes when calculated $I^{2}<50 \%[17,18]$. Probable publication bias was displayed not only by constructing a funnel plot, but also conducting Begg's test with rank correlation method and Egger's bias indicator test with linear regression method respectively [19-21]. $P$ values $<0.05$ was considered statistically significant.

\section{Results}

\section{Included literatures}

A total of 257 studies were retrieved from an initial online literature search that related to the prognosis and metastasis of HULC and cancer. After carefully screening the titles and abstracts, 234 articles were excluded according to the inclusion and exclusion criteria. For the remaining potential candidate studies, 23 articles were further reviewed of the full texts, 1 study was excluded as the specimen sources was not clearly described, 12 studies were then excluded because HULC was not a dichotomic variable in the original studies. As shown in Fig 1, the selection process with specification was presented by a flow diagram. Ultimately, the present meta-analysis was conducted for the remaining 10 articles.

Fig. 1. Flow diagram of the study search and selection process.

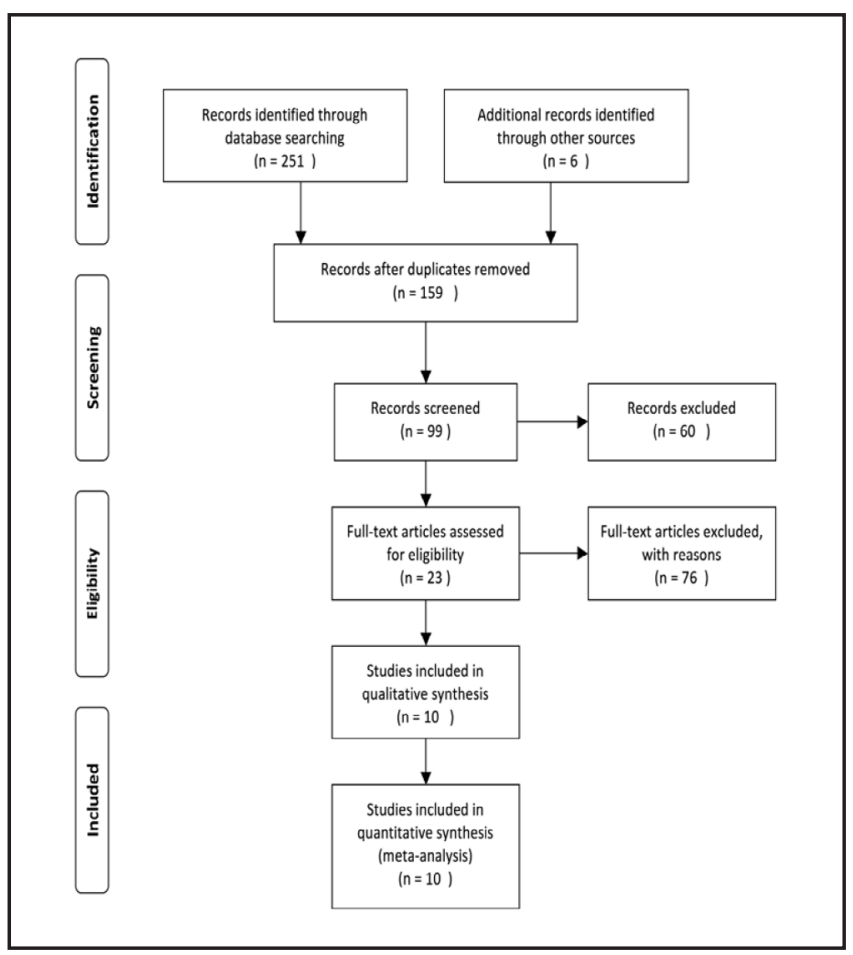




\section{Cellular Physiology Cell Physiol Biochem 2017;41:1424-1434 and Biochemistry Published \begin{tabular}{l|l} 
DOI: 10.1159/000468005 & $\begin{array}{l}\text { C } 2017 \text { The Author(s). Published by S. Karger AG, Basel } \\
\text { www.karger.com/cpb }\end{array}$
\end{tabular} \\ Chen et al.: A Meta-Analysis for HULC as a Prognostic Factor in Various Cancers}

Table 1. Summary of the ten included studies. Study design is described as retrospective (R); PC, Pancreatic cancer; OSA, osteosarcoma; GC, gastric cancer ; LBL, large B-cell lymphoma; CC, cervical cancer; DM, distant Metastasis; LNM, Lymph Node Metastasis; VM, Vascular metastasis

\begin{tabular}{|c|c|c|c|c|c|c|c|c|c|c|}
\hline Study & $\begin{array}{l}\text { Origin of } \\
\text { population }\end{array}$ & Study design & Disease & No.of patients & Stage & $\begin{array}{l}\text { HULC } \\
\text { assay }\end{array}$ & $\begin{array}{l}\text { Survival } \\
\text { analysis }\end{array}$ & Metastasis analysis & $\begin{array}{l}\text { Hazard } \\
\text { ratios }\end{array}$ & $\begin{array}{l}\text { Follow-up } \\
\text { Months }\end{array}$ \\
\hline Peng et al 2014 [22] & China & $\mathrm{R}$ & PC & 304 & NA & qRT-PCR & os & LNM/VM & $\mathrm{HR} / \mathrm{K}-\mathrm{M}$ & 60 \\
\hline Sun et al. 2015 [13] & China & $\mathrm{R}$ & OSA & 78 & IIA/IIB-III & qRT-PCR & os & DM & $\mathrm{HR} / \mathrm{K}-\mathrm{M}$ & 60 \\
\hline Jin et al. 2016 [23] & China & $\mathrm{R}$ & GC & 100 & I/II/III/IV & qRT-PCR & OS & LNM/DM & HR/K-M & 30 \\
\hline Li et al. 2016 [24] & China & $\mathrm{R}$ & $\mathrm{HCC}$ & 38 & I-II/III-IV & qRT-PCR & OS/RFS & DM & K-M & 60 \\
\hline Peng et al. 2016 [25] & China & $\mathrm{R}$ & LBL & 142 & I-II/III-IV & qRT-PCR & OS/PFS & NA & HR/ K-M & 60 \\
\hline Uzan et al. 2016 [26] & Brazil & $\mathrm{R}$ & OSA & 33 & I-II/III-IV & qRT-PCR & OS/EFS & DM & $\mathrm{K}-\mathrm{M}$ & 60 \\
\hline Wang et al. 2016 [27] & China & $\mathrm{R}$ & CC & 244 & IIb-IIIa/Ib-IIa & qRT-PCR & OS & LNM & HR/K-M & 60 \\
\hline Zhang et al. 2016 [28] & China & $\mathrm{R}$ & GC & 42 & NA & qRT-PCR & os & NA & K-M & 60 \\
\hline Xie et al. 2013 [29] & China & $\mathrm{R}$ & $\mathrm{HCC}$ & 30 & I-II/III-IV & qRT-PCR & NA & NA & NA & NA \\
\hline Li et al. 2015 [30] & China & $\mathrm{R}$ & HCC & 66 & I/II/III/IV & qRT-PCR & NA & NA & NA & NA \\
\hline
\end{tabular}

Fig. 2. Forest plot for the association between HULC expression with overall survival (OS).

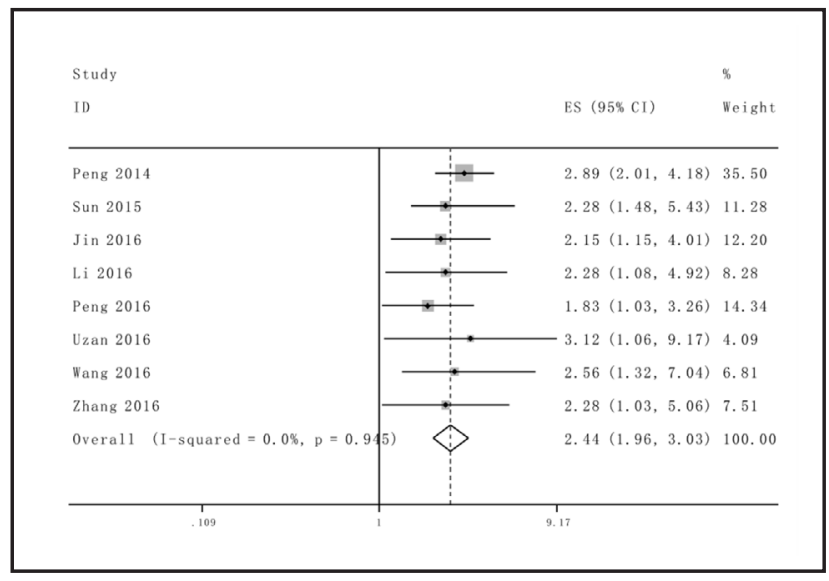

Characteristics of the enrolled studies

The main features of the 10 enrolled articles are summarized in Table 1 [13, 22-30]. These studies were published between 2013 and 2016 with sample sizes ranging from 30 to 304 . All of the 1077 patients were divided into two groups (high and low expression of HULC) according to the qRT-PCR measurement results. Nine of ten studies were from China and the patients were 6 types of carcinomas, including hepatocellular carcinoma, gastric cancer, pancreatic cancer, osteosarcoma, cervical cancer and large B-cell lymphoma. Of note, the median value was selected as the cut-off value in most articles.

\section{HULC and main outcome}

The fix effects model was used to analysis the pooled HR and its 95\% CI because no obvious heterogeneity among those 8 studies which involved in OS analysis $\left(I^{2}<50 \%\right)$. According to meta result in multivariate analysis, enforced HULC expression was predictive of unfavorable OS in various carcinomas (HR=2.44, 95\%CI: 1.96-3.03, $P=0.000$ ) (Fig. 2).

Afterwards the stratified analyses were performed by factor of country, cancer type, sample size and follow-up month to further analyze the clinical features of HULC (Table 2). For studies evaluating OS in different types of cancer, the results suggested that promoted HULC levels could estimate worse outcome in digestive system or non-digestive system malignancies, with the pooled HR of 2.57 (95\% CI: 1.96-3.38, $P=0.000$ ), and 2.21 (95\% CI: 1.54-3.17, $P=0.000$ ) respectively (Fig. 3A). A significant unfavorable association between HULC and OS of cancer patients was detected in China (HR=2.41,95\%CI: $1.93-3.01, P=0.000$ ) (Fig. 3B). Subsequently, we found that neither sample size nor follow up month alter the predictive value of HULC on the OS for all involved cancers (Fig. 3C and 3D). No significant heterogeneity was detected across studies within the subgroups. 
A

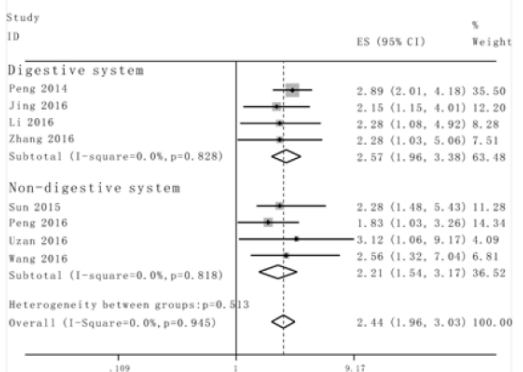

C

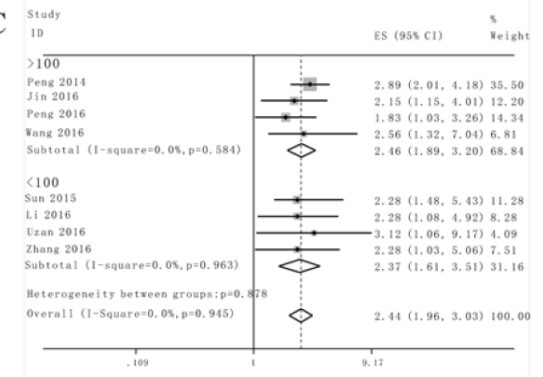

B

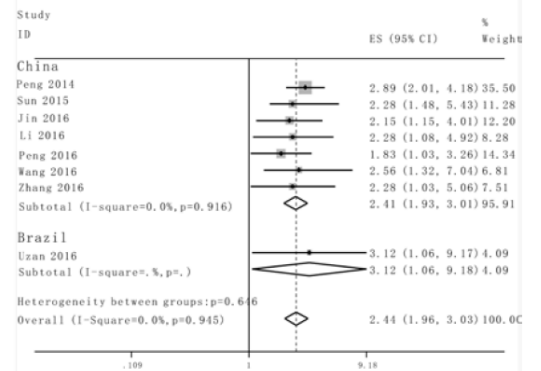

$\mathrm{D}$

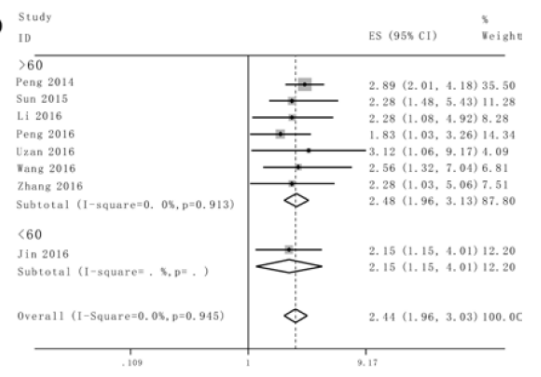

Fig. 3. Stratified analyses for the association between HULC expression with overall survival (OS). (A) Subgroup analysis of HRs of OS by factor of cancer type. (B) Subgroup analysis of HRs of OS by factor of residence region. (C) Subgroup analysis of HRs of OS by factor of sample size. (D) Subgroup analysis of HRs of OS by factor of follow up months.

Table 2. Subgroup analysis of the pooled HRs of overall survival with over-expressed HULC in patients with cancer

\begin{tabular}{|c|c|c|c|c|c|c|}
\hline \multirow[t]{2}{*}{ Subgroup analysis } & \multirow[t]{2}{*}{ No. of studies } & \multirow[t]{2}{*}{ No.of patients } & \multicolumn{2}{|c|}{ Pooled HR (95\% CI) } & \multicolumn{2}{|c|}{ Heterogeneity (Fix) } \\
\hline & & & Fix & $p$ Value & $I^{2}(\%)$ & $p$ Value \\
\hline \multicolumn{7}{|l|}{ Region } \\
\hline China & 7 & 948 & $2.41(1.93,3.01)$ & 0.000 & $0 \%$ & 0.916 \\
\hline \multicolumn{7}{|l|}{ Type of cancer } \\
\hline Digestive system & 4 & 484 & $2.57(1.96,3.38)$ & 0.000 & $0 \%$ & 0.828 \\
\hline Non-Digestive system & 4 & 497 & $2.21(1.54,3.17)$ & 0.000 & $0 \%$ & 0.818 \\
\hline \multicolumn{7}{|l|}{ Sample size } \\
\hline$\geq 100$ & 4 & 790 & $2.46(1.89,3.20)$ & 0.000 & $0 \%$ & 0.584 \\
\hline$<100$ & 4 & 191 & $2.37(1.61,3.51)$ & 0.000 & $0 \%$ & 0.963 \\
\hline \multicolumn{7}{|l|}{ Follow-up months } \\
\hline$\geq 60$ & 7 & 881 & $2.48(1.96,3.13)$ & 0.000 & $0 \%$ & 0.913 \\
\hline
\end{tabular}

Fig. 4. Fo-

rest plot for the association between HULC expression with TNM stage (III/ IV vs. I/II).

\begin{tabular}{|c|c|c|c|c|c|c|c|c|c|}
\hline Studv or Subgroup & $\begin{array}{c}\text { III NV } \\
\text { Events }\end{array}$ & Iotal & $\begin{array}{l}\text { I II } \\
\text { Events }\end{array}$ & & Weight & $\begin{array}{c}\text { Risk Ratio } \\
\text { M-H, Fixed, } 95 \% \mathrm{CI}\end{array}$ & \multicolumn{3}{|c|}{$\begin{array}{c}\text { Risk Ratio } \\
\text { M-H, Fixed, } 95 \% \mathrm{Cl}\end{array}$} \\
\hline Xie 2013 & 10 & 10 & 1 & 7 & $2.2 \%$ & $5.09[1.20,21.67]$ & & & \\
\hline Uzan 2016 & 4 & 9 & 8 & 21 & $5.9 \%$ & $1.17[0.47,2.90]$ & & 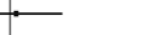 & \\
\hline Li 2016 & 12 & 15 & 11 & 23 & $10.8 \%$ & $1.67[1.02,2.75]$ & & 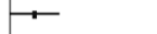 & \\
\hline Li 2015 & 11 & 16 & 22 & 50 & $13.2 \%$ & $1.56[0.99,2.46]$ & & $\leftarrow$ & \\
\hline $\operatorname{Jin} 2016$ & 34 & 56 & 14 & 44 & $19.4 \%$ & $1.91[1.18,3.09]$ & & $\rightarrow$ & \\
\hline Peng 2016 & 60 & 84 & 35 & 66 & $48.5 \%$ & $1.35[1.03,1.75]$ & & + & \\
\hline Total $(95 \%$ Cl) & & 190 & & 211 & $100.0 \%$ & $1.59[1.31,1.92]$ & & $\bullet$ & \\
\hline Total events & 131 & & 91 & & & & & & \\
\hline $\begin{array}{l}\text { Heterogeneity: } \mathrm{Ch}^{2}{ }^{2} \\
\text { Test for overall effect }\end{array}$ & $\begin{array}{l}5.03, \mathrm{df}= \\
Z=4.77(\mathrm{P}\end{array}$ & $\begin{array}{l}5(P=0 \\
P<0.00\end{array}$ & $\begin{array}{l}\text { (.41); } P^{2}= \\
0001)\end{array}$ & & & & $\begin{array}{ll}0.01 & 0.1 \\
\text { Favours [experimental] }\end{array}$ & $1 \frac{10}{1} \frac{10}{\text { Favours [control] }}$ & 100 \\
\hline
\end{tabular}

As shown in Fig. 4, increased HULC expression was found to be moderately associated with tumor stage and progression (III/IV vs. I/II: HR=1.59, 95\% CI: 1.31-1.92, P<0.00001). 
Table 3. Characteristics of studies included in the LNM meta-analysis

\begin{tabular}{lcccccc}
\hline & No. of & Method & \multicolumn{2}{c}{ HULC } & High & \multicolumn{2}{c}{ HULC } & Low \\
Study & patients & & Metastasis & Total & Metastasis & Total \\
\hline Peng et al. 2014 [22] & 304 & qRT-PCR & 157 & 212 & 23 & 92 \\
Jin et al. 2016 [23] & 100 & qRT-PCR & 34 & 48 & 25 & 52 \\
\hline
\end{tabular}

Table 4. Characteristics of studies included in the DM meta-analysis

\begin{tabular}{lcccccc}
\hline Study & No.of patients & Method & \multicolumn{2}{c}{ HULC } & High & \multicolumn{2}{c}{ HULC } & Low \\
& & & Metastasis & Total & Metastasis & Total \\
\hline Sun et al. 2015 [13] & 78 & qRT-PCR & 16 & 39 & 5 & 39 \\
Jin et al. 2016 [23] & 100 & qRT-PCR & 9 & 48 & 2 & 52 \\
Li et al. 2016 [24] & 38 & qRT-PCR & 8 & 23 & 1 & 15 \\
\hline
\end{tabular}

Fig. 5. Forest plot for the association between HULC expression with $\operatorname{DM}(\mathrm{A})$ and LNM (B).

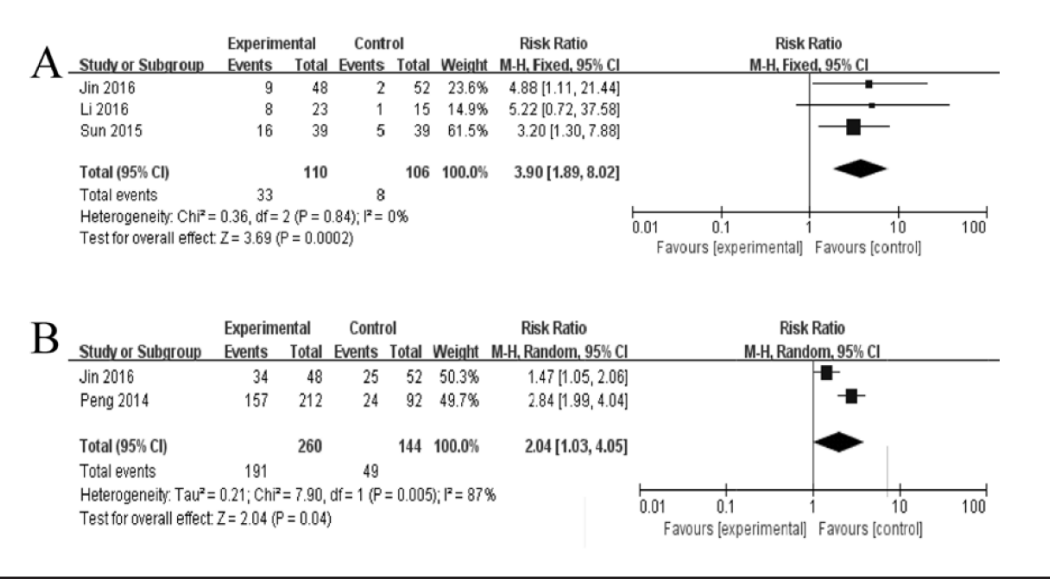

Fig. 6. Funnel plot of the publication bias for OS.

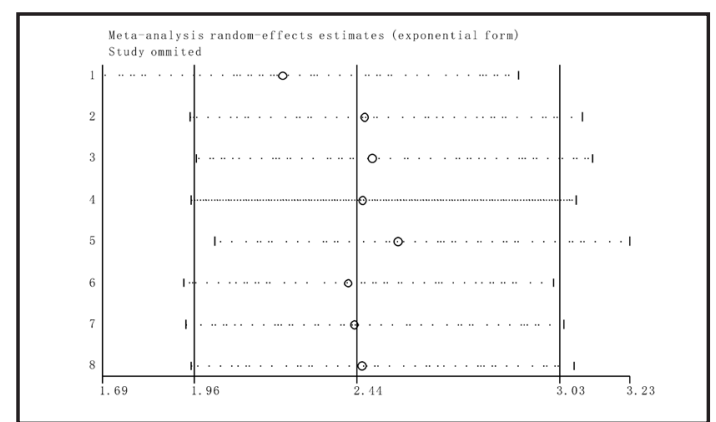

Fig. 7. Sensitivity of HULC expression for OS.

Overall, the pooled HRs revealed that HULC expression might be served as an unfavorable independent prognostic biomarker in various types of cancers.

\section{HULC and metastasis}

The characteristics of the involved studies which evaluating the association between HULC levels and cancer metastasis were summarized in Table 3 and 4. A fix model was performed to calculate the pooled HR and its $95 \% \mathrm{CI}$ when there is no obvious heterogeneity between studies $\left(I^{2}<50 \%\right)$. As shown in Fig. 5, elevated HULC expression significantly predicted DM (HR=3.90, 95\% CI: 1.89-8.02, $P=0.0002)$ and LNM (HR=2.04, 95\% CI: $1.03-$ $4.05, P=0.04$ ) respectively.

\section{Publication bias}

The potential publication bias of the present meta-analysis was evaluated by a funnel plot, Begg's test and Egger's test. No evidence of publication bias in the multivariate analysis 


\section{Cellular Physiology Cell Physiol Biochem 2017;41:1424-1434

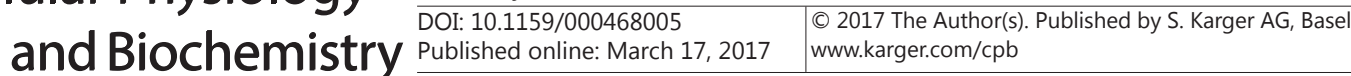

Table 5. MOOSE checklist

\begin{tabular}{|c|c|}
\hline \multicolumn{2}{|l|}{ Reporting of background should include } \\
\hline Problem definition & Background (Page 3) \\
\hline Hypothesis statement & Background (Page 3) \\
\hline Description of study outcome(s) & OS, RFS,PFS,EFS, LNM,VM,DM \\
\hline Type of exposure or intervention used & Various cancer (Page 3) \\
\hline Type of study designs used & Meta-analysis (Page 3) \\
\hline Study population & Global (Page 3) \\
\hline \multicolumn{2}{|l|}{ Reporting of search strategy should include } \\
\hline Qualifications of searchers (eg, librarians and investigators) & Investigator(Page 4) \\
\hline Search strategy, including time period included in the synthesis and keywords & $\begin{array}{l}\text { Search strategy and selection criteria } \\
\text { (Page 4) }\end{array}$ \\
\hline \multirow[t]{2}{*}{ Effort to include all available studies, including contact with authors } & We contact authors and searched \\
\hline & reference lists and citations (Page 4) \\
\hline Databases and registries searched & Methods (Page 3 ) \\
\hline Search software used, name and version, including special features used (eg, explosion) & IE 10 \\
\hline Use of hand searching ( $\mathrm{eg}$, reference lists of obtained articles) & $\begin{array}{l}\text { Search strategy and selection criteria } \\
\text { (Page 4) }\end{array}$ \\
\hline List of citations located and those excluded, including justification & Flow diagram in Figure 1. (Page 5) \\
\hline Method of addressing articles published in languages other than English & $\begin{array}{l}\text { Search strategy and selection criteria } \\
\text { (Page 4) }\end{array}$ \\
\hline Method of handling abstracts and unpublished studies & Method (Page 4) \\
\hline Description of any contact with authors & Method (Page 4) \\
\hline \multicolumn{2}{|l|}{ Reporting of methods should include } \\
\hline Description of relevance or appropriateness of studies assembled for assessing the hypothesis to be tested & Method (Page 4) \\
\hline Rationale for the selection and coding of data (eg, sound clinical principles or convenience) & Methods (Page 4) \\
\hline Documentation of how data were classified and coded (eg, multiple raters, blinding, and interrater reliability) & Methods (Page 4) \\
\hline Assessment of confounding (eg, comparability of cases and controls in studies where appropriate) & Methods (Page 4) \\
\hline Assessment of study quality, including blinding of quality assessors; stratification or regression on possible predictors of study & Methods (Page 4) \\
\hline \multicolumn{2}{|l|}{ results } \\
\hline Assessment of heterogeneity & Methods (Page 4) \\
\hline Description of statistical methods (eg, complete description of fixed or random effects models, justification of whether the chosen & Methods (Page 4) \\
\hline models account for predictors of study results, dose-response models, or cumulative meta-analysis) in sufficient detail to be & \\
\hline \multicolumn{2}{|l|}{ replicated } \\
\hline Provision of appropriate tables and graphics & Methods and Results (Page 4) \\
\hline \multicolumn{2}{|l|}{ Reporting of results should include } \\
\hline Graphic summarizing individual study estimates and overall estimate & Figure $2,3,4,5$ and 6 \\
\hline Table giving descriptive information for each study included & Table 1 \\
\hline Results of sensitivity testing (eg, subgroup analysis) & Meta-analysis (Page 6) \\
\hline Indication of statistical uncertainty of findings & Discussion (Page 6) \\
\hline \multicolumn{2}{|l|}{ Reporting of discussion should include } \\
\hline Quantitative assessment of bias (eg, publication bias) & Results (Page 5) \\
\hline Justification for exclusion (eg, exclusion of non-English-language citations) & Discussion (Page 6) \\
\hline Assessment of quality of included studies & Quality Assessment (Page 4) \\
\hline \multicolumn{2}{|l|}{ Reporting of conclusions should include } \\
\hline Consideration of alternative explanations for observed results & Discussion (Page 7) \\
\hline Generalisation of the conclusions (ie, appropriate for the data presented and within the domain of the literature review) & Discussion (Page 7) \\
\hline Guidelines for future research & Discussion (Page 8) \\
\hline Disclosure of funding source & Grant Support (Page 9) \\
\hline
\end{tabular}

of OS for Begg's and Egger's test. ( $P=0.23$ and $P=0.45)$, and the shapes of the funnel plot did not reveal any evidence of obvious asymmetry (Fig. 6).

Sensitivity analysis

The stability of the crude results was evaluated by sensitivity analysis. The results suggested that the conclusions are stable because the pooled HR was not significantly affected by the exclusion of any single study (Fig. 7).

\section{Discussion}

LncRNAs were defined as transcriptional noise in the past decades because most of them produced from intergenic and intronic regions of the genome and lack protein coding KARGER 


\section{Cellular Physiology Cell Physiol Biochem 2017;41:1424-1434

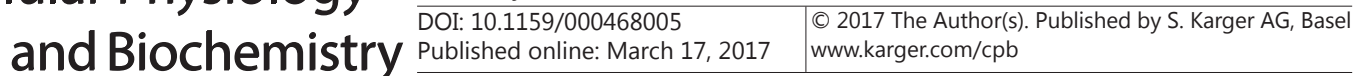

Table 6. PRISMA checklist

\begin{tabular}{|c|c|c|c|}
\hline Section/topic & $\#$ & Checklist item & $\begin{array}{l}\text { Reported on } \\
\text { page \# }\end{array}$ \\
\hline $\begin{array}{l}\text { Title } \\
\text { ABSTRACT }\end{array}$ & 1 & Identify the report as a systematic review, meta-analysis, or both. & 1 \\
\hline Structured summary & 2 & $\begin{array}{l}\text { Provide a structured summary including, as applicable: background; objectives; data sources; study eligibility criteria, participants, and interventions; study appraisal and } \\
\text { synthesis methods; results; limitations; conclusions and implications of key findings; systematic review registration number. }\end{array}$ & 2 \\
\hline INTRODUCTION & & & \\
\hline Rationale & 3 & Describe the rationale for the review in the context of what is already known. & 3 \\
\hline $\begin{array}{l}\text { Objectives } \\
\text { METHODS }\end{array}$ & 4 & Provide an explicit statement of questions being addressed with reference to participants, interventions, comparisons, outcomes, and study design (PICOS). & 3 \\
\hline $\begin{array}{l}\text { Protocol and } \\
\text { registration }\end{array}$ & 5 & Indicate if a review protocol exists, if and where it can be accessed (e.g., Web address), and, if available, provide registration information including registration number. & 4 \\
\hline Eligibility criteria & 6 & $\begin{array}{l}\text { Specify study characteristics (e.g., PICOS, length of follow-up) and report characteristics (e.g., years considered, language, publication status) used as criteria for eligibility, } \\
\text { giving rationale. }\end{array}$ & 4 \\
\hline Information sources & 7 & Describe all information sources (e.g., databases with dates of coverage, contact with study authors to identify additional studies) in the search and date last searched. & 4 \\
\hline Search & 8 & Present full electronic search strategy for at least one database, including any limits used, such that it could be repeated. & 4 \\
\hline Study selection & 9 & State the process for selecting studies (i.e., screening eligibility, included in systematic review, and, if applicable, included in the meta-analysis). & 4 \\
\hline Data collection process & 10 & Describe method of data extraction from reports (e.g. piloted forms, independently, in duplicate) and any processes for obtaining and confirming data from investigators. & 4 \\
\hline Data items & 11 & List and define all variables for which data were sought ( $\mathrm{eg}$., PICOS, funding sources) and any assumptions and simplifications made. & 4 \\
\hline $\begin{array}{l}\text { Risk of bias in } \\
\text { individual studies }\end{array}$ & 12 & $\begin{array}{l}\text { Describe methods used for assessing risk of bias of individual studies (including specification of whether this was done at the study or outcome level), and how this } \\
\text { information is to be used in any data synthesis. }\end{array}$ & 5 \\
\hline Summary measures & 13 & State the principal summary measures (e. $\mathrm{g}$, risk ratio, difference in means). & 5 \\
\hline Synthesis of results & 14 & Describe the methods of handling data and combining results of studies, if done, including measures of consistency (e.g., I²) for each meta-analysis. & 5 \\
\hline
\end{tabular}

capability [5, 31]. In recent years, tremendous contributions were made by scientists to the discovery that lncRNAs regulate the target gene expression and act as oncogenic or tumor suppressors [32-34]. With the rapid development of high-throughput genome-wide analysis technology, lncRNAs have been proposed as promising biomarkers for early detection and accurate prognosis for various carcinomas $[35,36]$.

As one of the promising novel biomarkers with high accuracy prognostic value for cancer patients, HULC has been noted to associate with diverse cellular processes, including migration, invasion, proliferation, differentiation, and apoptosis and are thereby prone to be involved in the tumorigenesis and progression [12, 14, 37, 38]. For example, HULC has been demonstrated to regulate hepatocellular cancer (HCC) proliferation through a miR9-mediated RXRA signaling pathway or suppressing the expression of tumor suppressor p18 $[39,40]$. Additionally, HULC may function as a competing endogenous RNA (ceRNA) in HCC that binds to and reduces the expression of a number of miRNAs. The reduction of miR-220a-3p and miR-372 leads to tumor progression through the miR-200a-3p/ZEB1 and miR-372/PRKACB signaling pathway respectively [24, 41]. Though a large number of studies have explored HULC interaction partners and molecular functions in various tumors, the mechanisms underlying HULC and tumor progression are still elusive.

Emerging evidence is encouraging that high expression of HULC serves as a convinced poor prognosis in several types of cancers, such as hepatocellular carcinoma, gastric cancer, pancreatic cancer, osteosarcoma, cervical cancer and large B-cell lymphoma. According to the urgently needed of potential prognostic biomarkers for individual therapy to the highrisk cancer patients, we firstly performed the present comprehensive and detailed metaanalysis to investigate the clinical prognostic role of HULC with a variety of carcinomas. Ten studies including 1077 patients were pooled in this study, and the results indicate that elevated HULC expression was significant correlated with poor prognosis, progression, DM and LNM in patients with various types of cancer. The analysis showed a pooled HR was 2.44 (95\% CI: 1.96-3.03, $P=0.000$ ), 1.59 (95\% CI: 1.31-1.92, $P<0.00001$ ), 3.90 (95\% CI: 1.898.02, $P=0.0002)$ and 2.04 (95\% CI: $1.03-4.05, P=0.04$ ) for OS, progression, DM and LNM respectively. 


\section{Cellular Physiology Cell Physiol Biochem 2017;41:1424-1434

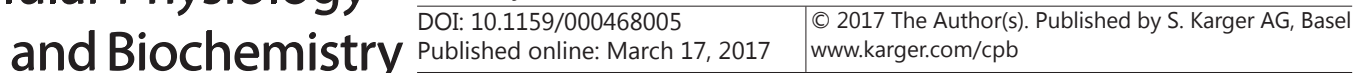 \\ Chen et al.: A Meta-Analysis for HULC as a Prognostic Factor in Various Cancers}

Nevertheless, it should be noted that there are several limitations of this study should be discussed. First, some of the HR were calculated by reconstructing survival curves rather than directly obtained from the primary studies. Second, cut off definition were not reported in some studies, and those reported were different in each study, which might weaken the reliability of our conclusion. In addition, the major patients included in our study were most from China and only one study was from Brazil. Because of this, our finding may just represent patients from Asia. After full texts of involved articles were reviewed, cancerous tissues were examined to determine HULC expression level in most cases, while serum samples were tested in one study. Of note, different specimen sources might be a further bias of the study. Finally, sample size of the study is too small. Only 10 studies with 1077 patients were included in the present meta-analysis. Therefore, we strongly suggest conducting more larger-size and better design studies to confirm our results.

In aggregate, even some limitations mentioned above, it was preliminarily concluded that promoted HULC may be considered as a credible unfavorable prognostic factor in human cancers. In the future, well designed larger-sample studies will be necessary to verify and strengthen the prognostic role of HULC in neoplasm patients.

\section{Acknowledgements}

The authors would like to thank the authors of the primary studies. The work was fully supported by the National Natural Science Foundation of China (No. 81501872 and No. 81601821), Distinguished Middle-Aged and Young Scientist Encourage and Reward Foundation of Shandong Province (No. BS2014YY034), China Postdoctoral Science Foundation (No. 2016M592144 and No. 2016M590621), Postdoctoral innovation project of Shandong Province (No. 201603069).

\section{Disclosure Statement}

The authors declare that there are no competing interests to disclose.

\section{References}

1 Bray F, Ren JS, Masuyer E, Ferlay J: Global estimates of cancer prevalence for 27 sites in the adult population in 2008. Int J Cancer 2013;132:1133-1145.

$>2$ Siegel RL, Miller KD, Jemal A: Cancer statistics, 2016. CA Cancer J Clin 2016;66:7-30.

3 Zhang Y, Lun L, Zhu B, Wang Q, Ding C, Hu Y, Huang W, Zhou L, Chen X, Huang H: Diagnostic accuracy of CD44V6 for osteosarcoma: a meta-analysis. J Orthop Surg Res 2016;11:133-141.

4 Zhang Y, Ding C, Wang J, Sun G, Cao Y, Xu L, Zhou L, Chen X: Prognostic significance of CD44V6 expression in osteosarcoma: a meta-analysis. J Orthop Surg Res 2015;10:187.

-5 Spizzo R, Almeida MI, Colombatti A, Calin GA: Long non-coding RNAs and cancer: a new frontier of translational research? Oncogene 2012;31:4577-4587.

6 Li T, Mo X, Fu L, Xiao B, Guo J: Molecular mechanisms of long noncoding RNAs on gastric cancer. Oncotarget 2016;7:8601-8612.

7 Mattick JS, Makunin IV: Non-coding RNA. Hum Mol Genet 2006;15:17-29.

8 Taft RJ, Pang KC, Mercer TR, Dinger M, Mattick JS: Non-coding RNAs: regulators of disease. J Pathol 2010;220:126-139.

9 Gibb EA, Brown CJ, Lam WL: The functional role of long non-coding RNA in human carcinomas. Mol Cancer 2011;10:38.

10 Li C, Chen J, Zhang K, Feng B, Wang R, Chen L: Progress and Prospects of Long Noncoding RNAs (lncRNAs) in Hepatocellular Carcinoma. Cell Physiol Biochem 2015;36:423-434. 


\section{Cellular Physiology Cell Physiol Biochem 2017;41:1424-1434 \begin{tabular}{ll|l} 
DOI: 10.1159/000468005 & $\begin{array}{l}\text { O 2017 The Author(s). Published by S. Karger AG, Basel } \\
\text { www.karger.com/cpb }\end{array}$
\end{tabular} \\ Chen et al.: A Meta-Analysis for HULC as a Prognostic Factor in Various Cancers}

11 Liu Y, Pan S, Liu L, Zhai X, Liu J, Wen J, Zhang Y, Chen J, Shen H, Hu Z: A genetic variant in long non-coding RNA HULC contributes to risk of HBV-related hepatocellular carcinoma in a Chinese population. PLoS One 2012; 7:e35145.

12 Gui X, Li H, Li T, Pu H, Lu D: Long Noncoding RNA CUDR Regulates HULC and beta-Catenin to Govern Human Liver Stem Cell Malignant Differentiation. Mol Ther 2015;23:1843-1853.

13 Sun XH, Yang LB, Geng XL, Wang R, Zhang ZC: Increased expression of IncRNA HULC indicates a poor prognosis and promotes cell metastasis in osteosarcoma. Int J Clin Exp Pathol 2015;8:2994-3000.

14 Zhao Y, Guo Q Chen J, Hu J, Wang S, Sun Y: Role of long non-coding RNA HULC in cell proliferation, apoptosis and tumor metastasis of gastric cancer: a clinical and in vitro investigation. Oncol Rep 2014;31:358-364.

15 Parmar MK, Torri V, Stewart L: Extracting summary statistics to perform meta-analyses of the published literature for survival endpoints. Stat Med 1998;17:2815-2834.

16 Tierney JF, Stewart LA, Ghersi D, Burdett S, Sydes MR: Practical methods for incorporating summary timeto-event data into meta-analysis. Trials 2007;8:16.

17 Higgins JP, Thompson SG: Quantifying heterogeneity in a meta-analysis. Stat Med 2002;21:1539-1558.

18 Bowden J, Tierney JF, Copas AJ, Burdett S: Quantifying, displaying and accounting for heterogeneity in the meta-analysis of RCTs using standard and generalised Q statistics. BMC Med Res Methodol 2011;11:41.

19 Begg CB, Mazumdar M: Operating characteristics of a rank correlation test for publication bias. Biometrics 1994;50:1088-1101.

20 Egger M, Davey Smith G, Schneider M, Minder C: Bias in meta-analysis detected by a simple, graphical test. BMJ 1997;315:629-634.

21 Light RJ, Pillemer DB: Summing up: the science of reviewing research. Cambridge, MA: Harvard University Press 1984;1:1.

-22 Peng W, Gao W, Feng J: Long noncoding RNA HULC is a novel biomarker of poor prognosis in patients with pancreatic cancer. Med Oncol 2014;31:346.

23 Jin C, Shi W, Wang F, Shen X, Qi J, Cong H, Yuan J, Shi L, Zhu B, Luo X, Zhang Y, Ju S: Long non-coding RNA HULC as a novel serum biomarker for diagnosis and prognosis prediction of gastric cancer. Oncotarget 2016; 7:51763-51772.

24 Li SP, Xu HX, Yu Y, He JD, Wang Z, Xu YJ, Wang CY, Zhang HM, Zhang RX, Zhang JJ, Yao Z, Shen ZY: LncRNA HULC enhances epithelial-mesenchymal transition to promote tumorigenesis and metastasis of hepatocellular carcinoma via the miR-200a-3p/ZEB1 signaling pathway. Oncotarget 2016;7:42431-42446.

25 Peng W, Wu J, Feng J: Long noncoding RNA HULC predicts poor clinical outcome and represents prooncogenic activity in diffuse large B-cell lymphoma. Biomed Pharmacother 2016;79:188-193.

-26 Uzan VR, Lengert A, Boldrini E, Penna V, Scapulatempo-Neto C, Scrideli CA, Filho AP, Cavalcante CE, de Oliveira CZ, Lopes LF, Vidal DO: High Expression of HULC Is Associated with Poor Prognosis in Osteosarcoma Patients. PLoS One 2016;11:e0156774.

27 Wang YF, Zhang S, Li XQ, Wang Y: Expression of lncRNA HULC in cervical cancer and its correlation with tumor progression and patient survival. Eur Rev Med Pharmacol Sci 2016;20:3987-3991.

28 Zhang Y, Song X, Wang X, Hu J, Jiang L: Silencing of LncRNA HULC enhances chemotherapy induced apoptosis in human gastric cancer. J Med Biochem 2016;35:137-143.

-29 Xie H, Ma H, Zhou D: Plasma HULC as a promising novel biomarker for the detection of hepatocellular carcinoma. Biomed Res Int 2013;2013:136106.

-30 Li J, Wang X, Tang J, Jiang R, Zhang W, Ji J, Sun B: HULC and Linc00152 Act as Novel Biomarkers in Predicting Diagnosis of Hepatocellular Carcinoma. Cell Physiol Biochem 2015;37:687-696.

31 Wilusz JE, Sunwoo H, Spector DL: Long noncoding RNAs: functional surprises from the RNA world. Genes Dev 2009;23:1494-1504.

-32 Zhang H, Chen Z, Wang X, Huang Z, He Z, Chen Y: Long non-coding RNA: a new player in cancer. J Hematol Oncol 2013;6:37.

-33 Maruyama R, Suzuki H: Long noncoding RNA involvement in cancer. BMB Rep 2012;45:604-611.

34 Pan Y, Li C, Chen J, Zhang K, Chu X, Wang R, Chen L: The Emerging Roles of Long Noncoding RNA ROR (lincRNA-ROR) and its Possible Mechanisms in Human Cancers. Cell Physiol Biochem 2016;40:219-229.

-35 Wu Y, Zhang L, Wang Y, Li H, Ren X, Wei F, Yu W, Wang X, Yu J, Hao X: Long noncoding RNA HOTAIR involvement in cancer. Tumour Biol 2014;35:9531-9538. 


\section{Cellular Physiology Cell Physiol Biochem 2017;41:1424-1434 \begin{tabular}{ll|l} 
DOI: 10.1159/000468005 & O 2017 The Author(s). Published by S. Karger AG, Basel \\
www.karger.com/cpb
\end{tabular}

-36 Deng Q, Sun H, He B, Pan Y, Gao T, Chen J, Ying H, Liu X, Wang F, Xu Y, Wang S: Prognostic value of long noncoding RNA HOTAIR in various cancers. PLoS One 2014; 9:e110059.

-37 Yang XJ, Huang CQ, Peng CW, Hou JX, Liu JY: Long noncoding RNA HULC promotes colorectal carcinoma progression through epigenetically repressing NKD2 expression. Gene 2016; 592:172-178.

-38 Zhu Y, Zhang X, Qi L, Cai Y, Yang P, Xuan G, Jiang Y: HULC long noncoding RNA silencing suppresses angiogenesis by regulating ESM-1 via the PI3K/Akt/mTOR signaling pathway in human gliomas. Oncotarget 2016;7:14429-14440.

-39 Cui M, Xiao Z, Wang Y, Zheng M, Song T, Cai X, Sun B, Ye L, Zhang X: Long noncoding RNA HULC modulates abnormal lipid metabolism in hepatoma cells through an miR-9-mediated RXRA signaling pathway. Cancer Res 2015;75:846-857.

40 Du Y, Kong G, You X, Zhang S, Zhang T, Gao Y, Ye L, Zhang X: Elevation of highly up-regulated in liver cancer (HULC) by hepatitis B virus X protein promotes hepatoma cell proliferation via down-regulating p18. J Biol Chem 2012;287:26302-26311.

41 Wang J, Liu X, Wu H, Ni P, Gu Z, Qiao Y, Chen N, Sun F, Fan Q: CREB up-regulates long non-coding RNA, HULC expression through interaction with microRNA-372 in liver cancer. Nucleic Acids Res 2010;38:5366-5383. 